\title{
NASOPHARYNGEAL STREPTOCOCCUS PNEUMONIAE CARRIAGE IN ALGERIAN HEALTHY CHILDREN BEFORE AND POST 13 VALENT PNEUMOCOCCAL CONJUGATE VACCINE IMPLEMENTATION
}

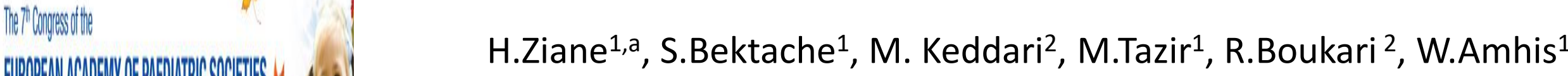

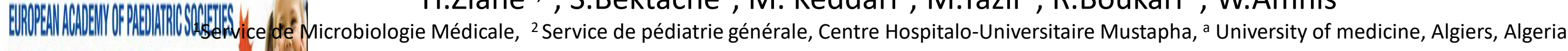

e.mail: h.zianedz@hotmail.fr

Background

S.pneumoniae serotypes in colonization should be an indicator for invasive infections. Since June 2016 , PCV13 was implemented nationwide in Algeria. Nasopharyngeal carriage of S.pneumoniae has allowed in Algiers, to assess its rate, antibiotic resistance and serotypes implicated in pre and post vaccine periods.

\section{Results}

Prevalence of S.pneumoniae nasopharyngeal carriage in asymptomatic children was $28.3 \%$ and $33 \%$ in pre and post vaccine periods respectively.

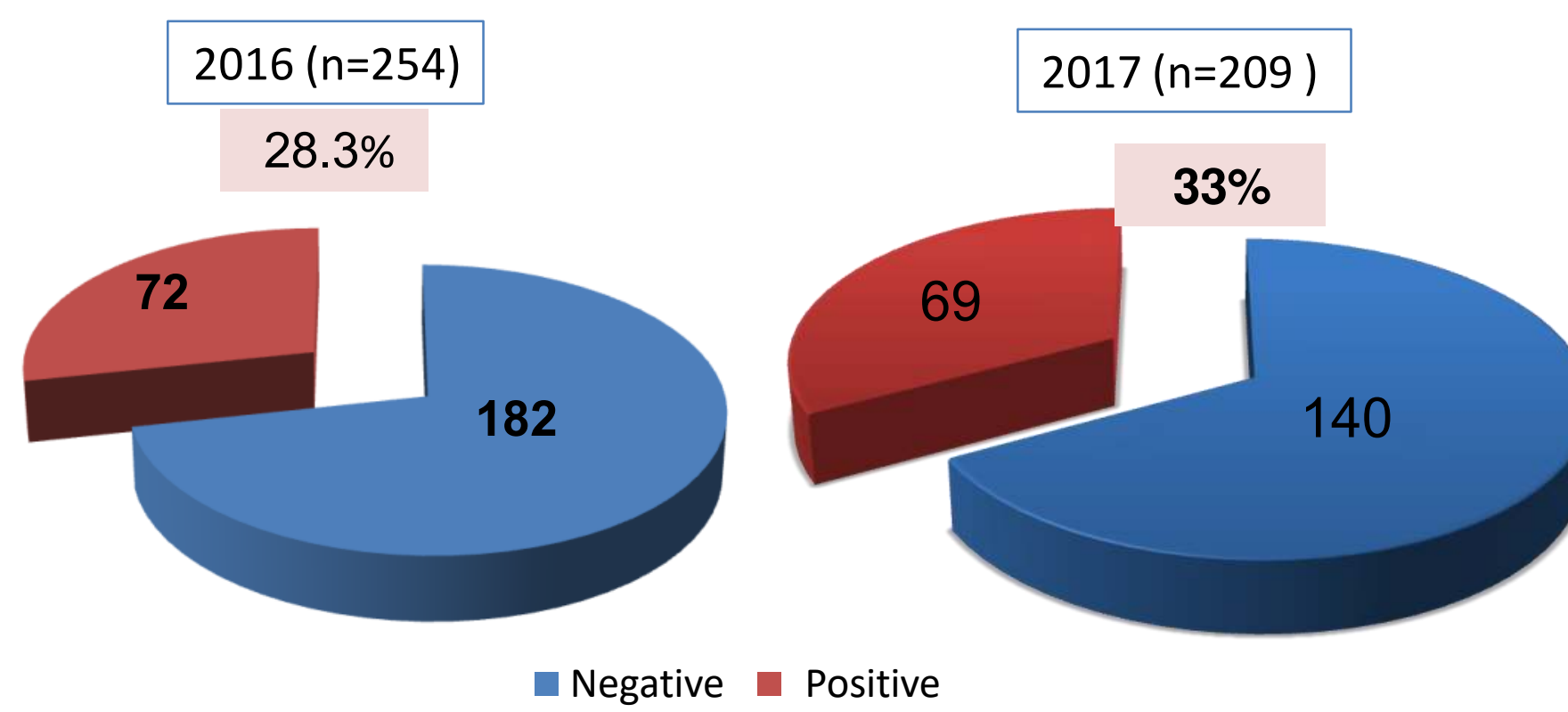

Figure 1. Prevalence in asymptomatic S.pneumoniae carriage in 2016 and 2017

\begin{tabular}{ccccc|}
\hline Age (months) & $\begin{array}{c}\text { Total } \\
\text { (num) }\end{array}$ & $\begin{array}{c}\text { Pre-vaccine period } \\
\text { S.pneumoniae carriage } \\
\text { (\%) }\end{array}$ & $\begin{array}{c}\text { Total } \\
\text { (num) }\end{array}$ & $\begin{array}{c}\text { Post vaccine period } \\
\text { S.pneumoniae carriage } \\
\text { (\%) }\end{array}$ \\
\hline $0-6]$ & 160 & 28.1 & 104 & 28.8 \\
] $6-12]$ & 42 & 31 & 12 & 33.3 \\
] $12-24]$ & 35 & 22.9 & 78 & 37.2 \\
] $24-60]$ & 17 & 11.8 & 15 & 40 \\
$\begin{array}{c}\text { Average age } \\
\text { (months) }\end{array}$ & 9.6 & 7.9 & & 13.6 \\
\hline
\end{tabular}

\section{Discussion}

* Rates of S. pneumoniae asymptomatic carriage in children less 5 years old vary in the country according to the study periods. It was at 32\% in 2012 [2] , 28.3\% in 2016 and 33\% in 2017.

* Penicillin non-susceptible (MIC $\geq 0.12 \mu \mathrm{g} / \mathrm{ml}$ ) Pneumococcus was higher than described in 2012(69.4\%). However, PGMIC $\geq 2 \mu \mathrm{g} / \mathrm{ml}$ determined by Walk Away must be confirmed by E.Tests

* Erythromycin, co-trimoxazole. and tetracycline are markers of multi drug resistance which was reported at $>42 \%$.

* Children were co-colonized with pneumococci belonging to two different serogroup/types in

$9.7 \%$ and $14.5 \%$ in pre and post vaccine periods respectively.

* In pre and post vaccine periods, vaccine serotypes $6 \mathrm{~A} / \mathrm{B}, 19 \mathrm{~F}$, and $23 \mathrm{~F}$ were

the most common and the most resistant in rates and levels to antibiotics

* Serotypes 14 and 19A are less frequent than in 2012.

* Non-conjugate vaccine serotypes accounted for $25.5 \%$ in 2016 and 34.5\% in 2017.

Serotype 15A/B was the predominant.

* The 13-valent conjugate vaccine covered $74.5 \%$ of all serotypes in 2016 and $65.3 \%$ in 2017.

* Multiplex PCR used for pneumococcus serotyping is applicated for the first time in Algeria

* The 54 isolates remained non typeable by multiplex PCR must be performed by Quellung reaction.

\section{Conclusion}

\section{Materiel and methods} and post vaccine (February to May 2017) periods at Laboratory of Clinical No duplicative 254 and 209 asymptomatic healthy children aged 0-60 months included respectively.

作 susceptibility testing was determined by an agar disk diffusion

Capsular serotyping was done using multiplex PCR and Quellung reaction with

Table 2. S.pneumoniae antibiotic resistance in carriage considering periods

\begin{tabular}{|ccc|}
\hline $\begin{array}{c}\text { Antibiotic } \\
\text { Resistance (\%) }\end{array}$ & $\begin{array}{c}\text { Pre-vaccine period } \\
\mathbf{2 0 1 6}\end{array}$ & $\begin{array}{c}\text { Post vaccine period } \\
\mathbf{2 0 1 7}\end{array}$ \\
\hline Penicillin G & & \\
& & \\
MIC $\geq \mathbf{0 , 1 2} \boldsymbol{\mu g} / \mathrm{ml}$ & 57,4 & 49,3 \\
MIC $\geq \mathbf{2} \boldsymbol{\mu g} / \mathrm{ml}$ & 22,2 & 30,4 \\
& & \\
Erythromycin & 68,5 & 63,8 \\
Co-trimoxazole & 54 & 26 \\
Tetracycline & 48,6 & 61,8 \\
\hline
\end{tabular}

Table 3. S.pneumoniae serogroups/types implicated in children asymptomatic carriage shown by period.

\begin{tabular}{|c|c|c|c|}
\hline $\begin{array}{c}\text { Serogroups } \\
\text { Serotypes } \\
\text { (num) }\end{array}$ & $\begin{array}{l}\text { Pre-vaccine } \\
\text { period }\end{array}$ & $\begin{array}{l}\text { Post vaccine } \\
\text { period }\end{array}$ & Total \\
\hline 4 & 0 & 0 & 0 \\
\hline $6 A / B$ & 15 & 14 & 29 \\
\hline $9 V / A$ & 2 & 1 & 3 \\
\hline 14 & 3 & 2 & 5 \\
\hline $18 \mathrm{C}$ & 1 & 1 & 2 \\
\hline $19 \mathrm{~F}$ & 7 & 8 & 15 \\
\hline $23 F$ & 11 & 4 & 15 \\
\hline 1 & 0 & 0 & 0 \\
\hline 5 & 0 & 0 & 0 \\
\hline $7 F$ & 0 & 1 & 1 \\
\hline 3 & 0 & 0 & 0 \\
\hline 19A & 2 & 1 & 3 \\
\hline Sub Total & 41 & 32 & 73 \\
\hline \multicolumn{4}{|l|}{$\begin{array}{c}\text { Non conjugate } \\
\text { vaccine serotypes }\end{array}$} \\
\hline $15 \mathrm{~A} / \mathrm{B}$ & 6 & 9 & 15 \\
\hline $10 A$ & 2 & 3 & 5 \\
\hline $11 \mathrm{~A}$ & 0 & 3 & 3 \\
\hline 17 & 1 & 0 & 1 \\
\hline 8 & 1 & 1 & 2 \\
\hline 35B & 0 & 1 & 1 \\
\hline $\mathbf{G}$ & 3 & 0 & 3 \\
\hline I & 1 & 0 & 1 \\
\hline Subtotal & 14 & 17 & 31 \\
\hline Non -Typeable & 24 & 30 & 54 \\
\hline Sub Total & 38 & 47 & 85 \\
\hline Total & 79 & 79 & 158 \\
\hline
\end{tabular}

Natural or vaccine-induced fluctuations occur over time in serotypes distribution and antibiotic resistance. Therefore, regular monitoring of serotypes distribution in carriage of S.pneumoniae is important after vaccine implementation in Algeria.

\section{References}

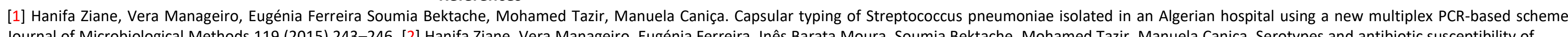
Journal of Microbiological Methods 119 (2015) 243-246. [2] Hanifa Ziane, Vera Manageiro, Eugénia Ferreira, Inês Barata Moura, Soumia Bektache, Mohamed Tazir, Manuela Caniça. Serotypes and antibiotic susceptibility of Streptococcus pneumoniae isolates from invasive pneumococcal disease and asymptomatic carriage in a pre-vaccination period, in Algeria .Front Microbiol. 2016; 7: 803 